\title{
Corrosion-Electrochemical Behavior of Nickel in an Alkali Metal Carbonate Melt under a Chlorine-Containing Atmosphere
}

\author{
E. V. Nikitina*, V. Ya. Kudyakov, V. B. Malkov, and S. V. Plaksin \\ Institute of High-Temperature Electrochemistry, Ural Branch, Russian Academy of Sciences, \\ Yekaterinburg, 620219 Russia \\ Ural State University, pr. Lenina 51, Yekaterinburg, 620083 Russia \\ *e-mail: neekeetina@mail.ru \\ Received January 20, 2013
}

\begin{abstract}
The corrosion-electrochemical behavior of a nickel electrode is studied in the melt of lithium, sodium, and potassium ( $40: 30: 30 \mathrm{~mol} \%)$ carbonates in the temperature range $500-600^{\circ} \mathrm{C}$ under an oxidizing atmosphere $\mathrm{CO}_{2}+0.5 \mathrm{O}_{2}(2: 1)$, which is partly replaced by gaseous chlorine $(30,50,70 \%)$ in some experiments. In other experiments, up to $5 \mathrm{wt} \%$ chloride of sodium peroxide is introduced in a salt melt. A change in the gas-phase composition is shown to affect the mechanism of nickel corrosion.
\end{abstract}

DOI: $10.1134 / \mathrm{S} 0036029513080107$

\section{INTRODUCTION}

The corrosion characteristics of nickel have been extensively studied over the last decades, which is related to its application as an electrode material for various electrochemical devices. A nonconsumable anode made of nickel oxide must be stable in a melt and have a sufficient mechanical strength and thermal resistance. In contrast, the formation of an electrode for a melt-carbonate current source requires a high electrochemical activity of the forming oxide, which is possible for a developed surface and the optimum number and size of pores. The corrosion losses of nickel are substantially determined by the composition of the atmosphere over a melt [1], the solubility of gases in carbonate melts is a rather small and almost constant magnitude, and this solubility decreases with increasing temperature [2].

When studying the oxidation and lithiation of nickel in a carbonate melt under the operating conditions of a melt-carbonate fuel cell, the authors of [3-11] found that the rate-controlling step of this process is the diffusion of oxygen toward the electrode surface. Partial replacement of an atmosphere made of a mixture of oxygen and carbon dioxide over a carbonate melt by gaseous chlorine should affect the corrosion and the $I-V$ characteristics of a nickel electrode. A change in the salt phase composition by introducing oxygen- or halogen-containing additives can also affect the corrosion characteristics of a nickel electrode.

\section{EXPERIMENTAL}

In all experiments, we used a eutectic mixture of lithium, sodium, and potassium carbonates as an electrolyte. We took analytical grade salts for its prepara- tion. As a reference electrode, we applied the standard gas diffusion electrode $\left(\mathrm{Li}_{0.4}, \mathrm{Na}_{0.3}, \mathrm{~K}_{0.3}\right)_{2} \mathrm{CO}_{3}$ (eut)/ $\mathrm{Pt}$, $\mathrm{CO}_{2}+\mathrm{O}_{2}(2: 1)$ with a $\gamma-\mathrm{Al}_{2} \mathrm{O}_{3}$ jacket, and electrical contact with the cell electrolyte took place due to the porosity of alundum.

Experiments were carried out in a three-electrode cell, and the working electrode consisted of an $\mathrm{N} 0$ nickel parallelepiped with a total area of $4 \mathrm{~cm}^{2}$, which was fully submerged into a melt and suspended by a platinum wire. As a counter electrode, we used a platinum plate with an area of $10 \mathrm{~cm}^{2}$. For measurements, we employed a PI 50-1 potentiostat, a PR 8 programmer, and a two-axis detecting device.

Chlorine was produced by the electrolysis of the lead(II) chloride melt and supplied to the cell after bubbling through sulfuric acid. The percentage composition of the gas mixture $(1: 2,1: 1,2: 1)$ was determined from the pressure ratio of chlorine to a mixture of carbon dioxide and oxygen.

The morphology of the corrosion products was studied by electron-probe microanalysis and X-ray diffraction (XRD). A salt melt was analyzed by gravimetry and atomic absorption spectroscopy.

\section{RESULTS AND DISCUSSION}

The addition of sodium peroxide to a salt melt significantly increases the metal passivation, since anode anion polarization is hindered on a nickel electrode covered with a dense layer of nickel oxide. The corrosion rate increases with the peroxide concentration, the yield of nickel to the melt is almost constant (Table 1), and the corrosion potential shifts insignificantly toward electrically positive values for each tempera- 
Table 1. Corrosion characteristics at $600^{\circ} \mathrm{C}$ of nickel in a melt of alkali metal carbonates containing sodium peroxide

\begin{tabular}{c|c|c|c|c}
\hline $\mathrm{Na}_{2} \mathrm{O}_{2}, \mathrm{wt} \%$ & $\Delta P, \mathrm{~g} / \mathrm{m}^{2}$ & Yield of Ni in melt, $\mathrm{g} / \mathrm{m}^{2}$ & $K, \mathrm{~g} / \mathrm{m}^{2}$ & $-E_{\text {cor }}, \mathrm{V}$ \\
\hline 0.5 & 4.68 & 0.01 & 4.69 & 0.80 \\
0.95 & 8.23 & 0.017 & 8.24 & 0.81 \\
1.5 & 9.72 & 0.023 & 3.74 & 0.82 \\
2.0 & 10.83 & 0.04 & 10.87 & 0.81 \\
\hline
\end{tabular}

Table 2. Corrosion characteristics at $600^{\circ} \mathrm{C}$ of nickel in a melt of alkali metal carbonates containing sodium chloride

\begin{tabular}{c|c|c|c|c}
\hline $\mathrm{NaCl}$, wt $\%$ & $\Delta P, \mathrm{~g} / \mathrm{m}^{2}$ & Yield of Ni in melt, $\mathrm{g} / \mathrm{m}^{2}$ & $K, \mathrm{~g} / \mathrm{m}^{2}$ & $-E_{\text {cor }}, \mathrm{V}$ \\
\hline 0.63 & 8.09 & $0.02(0.14)$ & 18.19 & 0.81 \\
1.12 & 12.84 & $0.02(0.21)$ & 10.7 & 0.88 \\
1.5 & 13.9 & $1.013(0.38)$ & 10.35 & 0.88 \\
2.0 & 18.58 & $7.87(0.59)$ & 14.76 & 0.89 \\
\hline
\end{tabular}

Table 3. Corrosion losses of a nickel electrode during anodic polarization in a melt of alkali metal carbonates

\begin{tabular}{c|c|c|c}
\hline$T,{ }^{\circ} \mathrm{C}$ & $\Delta P, \mathrm{~g} / \mathrm{m}^{2}$ & Yield of $\mathrm{Ni}$ in melt, $\mathrm{g} / \mathrm{m}^{2}$ & $\mathrm{Cl}_{2}$ in atmosphere above melt, $\%$ \\
\hline 500 & -23.3 & 35.3 & 30 \\
600 & -24.6 & 38.7 & 30 \\
500 & -22.3 & 52.6 & 50 \\
600 & -27.3 & 37.1 & 70 \\
500 & -36.5 & 82.3 & 70 \\
600 & -49.0 & 94.1 & 0 \\
500 & 2.3 & 0.7 & 0 \\
600 & 3.2 & 2.3 & \\
\hline
\end{tabular}

ture. The introduction of sodium chloride into the melt slightly increases the corrosion rate, and the corrosion potential shifts weakly toward electrically negative values for each temperature (Table 2).

The anode potentiostatic polarization curve of nickel in a melt containing sodium peroxide or halide is almost identical to that without additives.
The introduction of chlorine in the gas phase leads to significant passage of nickel into the melt and to local corrosion fracture (Table 3 ). The corrosion potential lies in the range from -0.8 to $-0.7 \mathrm{~V}$.

An increase in the chlorine content or the temperature during anodic potentiostatic polarization under a chlorine-containing atmosphere results in an

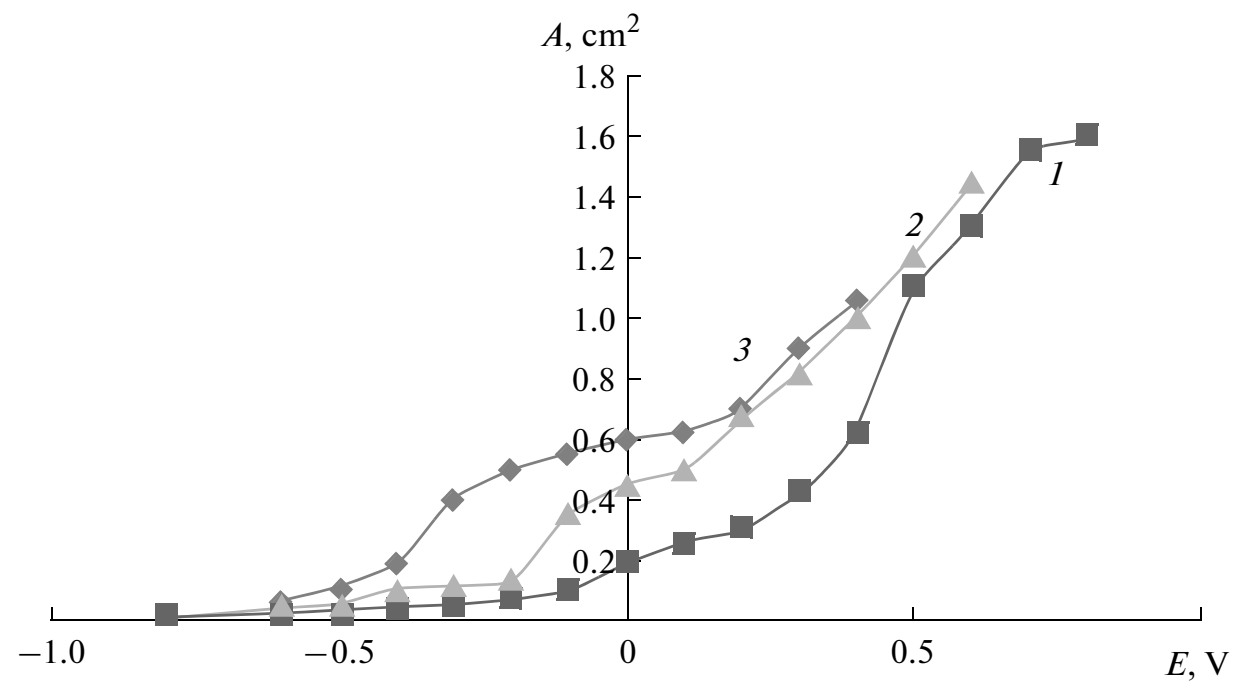

Fig. 1. Anodic potentiostatic polarization of a nickel electrode in a melt of alkali metal carbonates under an atmosphere containing (1) 30 , (2) 50, and (3) $70 \mathrm{vol} \%$ gaseous chlorine. 
increase in the current density: the currents in the corresponding curves exceed those recorded during polarization under other atmospheres by a factor of 5-10. An increase in the chlorine content in the atmosphere over the melt leads to an increase in the current density in the anodic region.

After measurements, the electrodes were washed in distilled water. At 30 and $50 \%$ chlorine in the atmosphere over the melt, the samples were coated with a dense dark green film having good adhesion to the base, and local corrosion manifested itself along the periphery of the samples. This corrosion damages increased with temperature. After washing, the layer of corrosion products consisted of dense nickel(II) oxide with a particle size of about $10 \mathrm{~nm}$ (Fig. 2a). At 70\% chlorine, the film on samples had a lower density and changed its color from black-green to black at the electrode ends (Fig. 2b). An increase in the chlorine content or the temperature during anodic potentiostatic polarization under a chlorine-containing atmosphere results in an increase in the current density: the currents in the corresponding curves exceed those recorded during polarization under other atmospheres by a factor of 5-10.

After measurements, the electrodes were washed in distilled water. As a result, nickel(II) chloride dissolved and oxide was only retained in corrosion fracture zones. At 30 and $50 \%$ chlorine in the cell atmosphere, the samples were coated with a dense dark green film having good adhesion to the base. Local corrosion damages were maximal in depth and number along the periphery of the samples, and this phenomenon increased with temperature (Fig. 2c).

Gaseous chlorine is an active gas relative to a carbonate melt. A carbonate melt, first, dissolves chlorine and, second, interacts with it. Oxygen-containing chlorine compounds can form as intermediate products; as a result, sodium chloride and a mixture of oxygen and carbon dioxide can form. For example, lithium carbonate interacts with gaseous chlorine according to the reaction

$$
\begin{gathered}
2 \mathrm{Li}_{2} \mathrm{CO}_{3}+2 \mathrm{Cl}_{2}=4 \mathrm{LiCl}+2 \mathrm{CO}_{2}+\mathrm{O}_{2} \\
\left(\Delta G^{773}=-179.2 \mathrm{~kJ} ; \Delta G^{873}=-203.1 \mathrm{~kJ}\right) .
\end{gathered}
$$

The solubility of oxygen is one millionth of a mole fraction, and the solubility of chlorine in the melt is considered to be a comparable magnitude. The introduction of chlorine in the melt should not decrease the oxygen content.

The rate-controlling step of the corrosion process is the diffusion of oxidizers toward the electrode surface. In the absence of external polarization, the oxidation of nickel in the melt occurs as a corrosion process with oxygen depolarization,

$$
2 \mathrm{Ni}+\mathrm{O}_{2}=2 \mathrm{NiO} \text {. }
$$
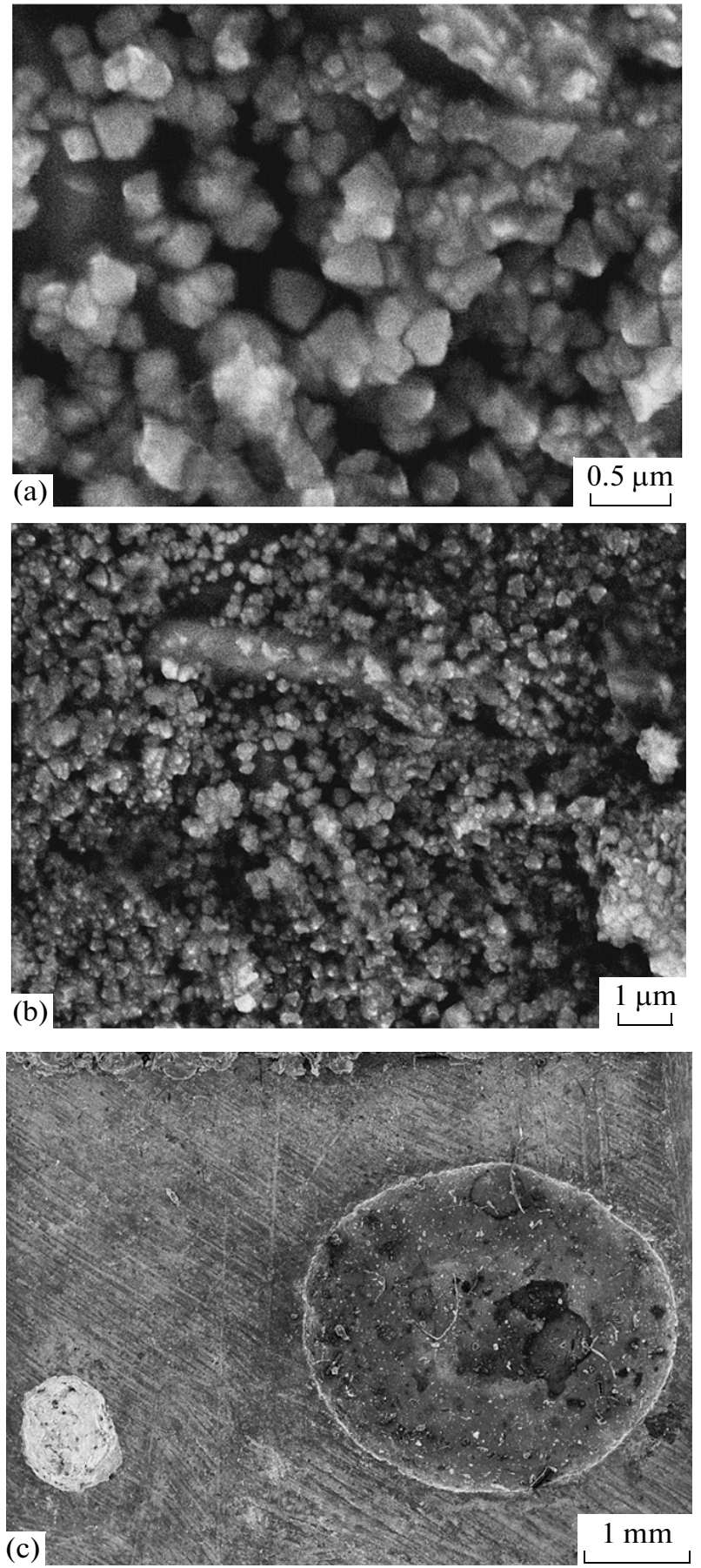

Fig. 2. Electron micrographs of a nickel electrode after anodic polarization in a carbonate melt under a chlorinecontaining atmosphere: (a) $30 \% \mathrm{Cl}_{2}, 500^{\circ} \mathrm{C}$; (b) $70 \% \mathrm{Cl}_{2}$, $500^{\circ} \mathrm{C}$; and (c) $70 \% \mathrm{Cl}_{2}, 600^{\circ} \mathrm{C}$.

In the absence of anodic polarization, the interaction of nickel with chlorine,

$$
\mathrm{Ni}+\mathrm{Cl}_{2}=\mathrm{NiCl}_{2}
$$

is possible from a standpoint of thermodynamics and is impossible from a standpoint of kinetics, since nickel in a carbonate melt is always covered with an 


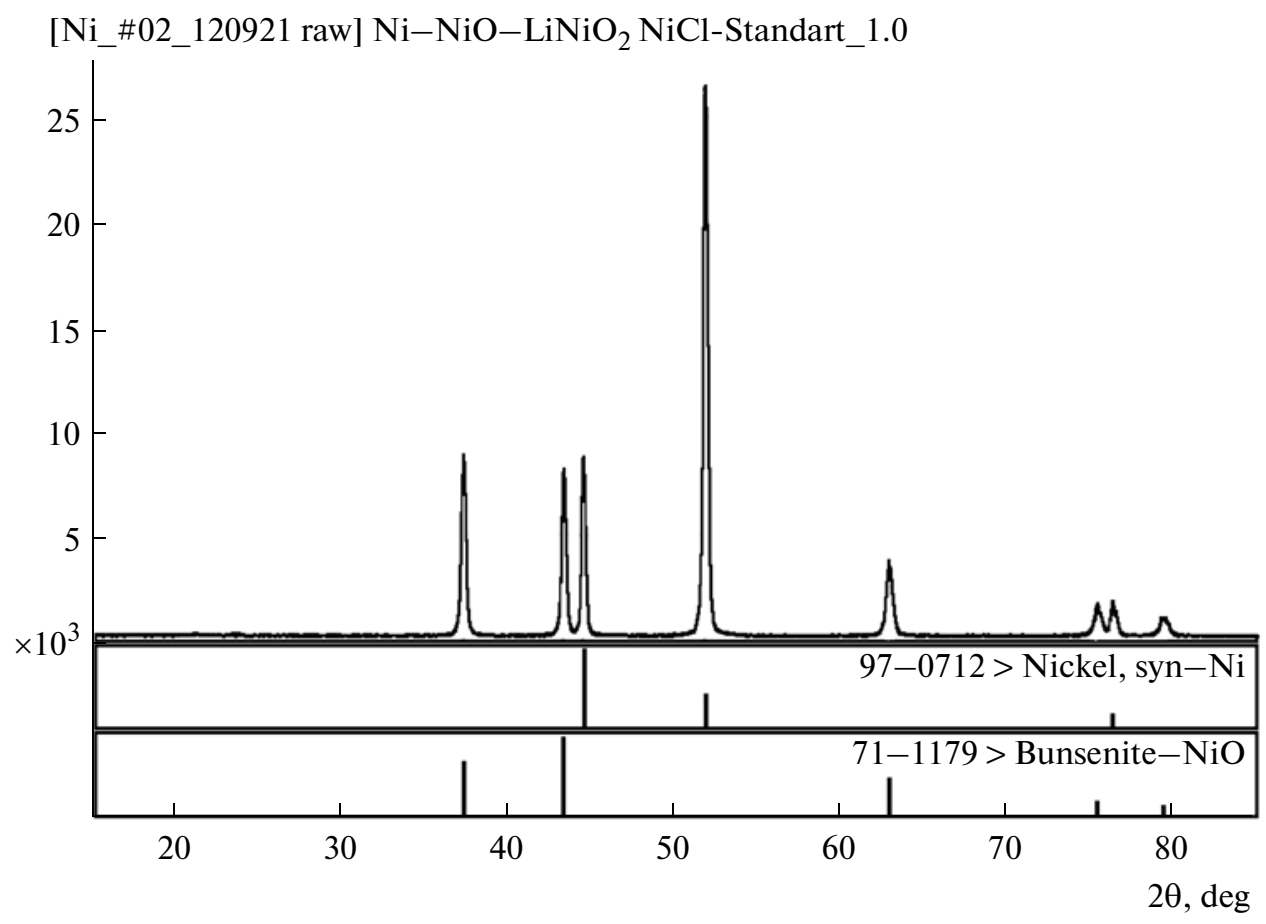

Fig. 3. X-ray diffraction pattern of a nickel electrode after anodic potentiostatic polarization in a chlorine-containing atmosphere.

oxide film. The compromise electrode potential is determined by the corrosion current. The time dependence of the potential strongly depends on the gas atmosphere composition and weakly depends on small amounts of artificial additives to the salt phase.

At the first stage of polarization (from -0.8 to $-0.6 \mathrm{~V}$ ), the oxidized forms of nickel pass to the melt and the electrode behaves like an electrode of the first kind. The electrode potential is determined by the activity of nickel ions in the melt. An increase in the partial pressure of chlorine leads to an increase in the current density, which is related to an increase in the solubility of nickel oxide according to the reaction [12]

$$
\mathrm{NiO}+\mathrm{Cl}_{2}=\mathrm{NiCl}_{2}+0.5 \mathrm{O}_{2}
$$

and the reaction

$$
\mathrm{Ni}-2 \mathrm{e}+2 \mathrm{Cl}^{-}=\mathrm{NiCl}_{2} \text {. }
$$

Table 4. Chemical analysis of frozen melt samples, \%

\begin{tabular}{c|c|c}
\hline $\begin{array}{c}\text { Chlorine in atmo- } \\
\text { sphere above melt }\end{array}$ & $\begin{array}{c}\text { Chlorine in solidi- } \\
\text { fied melt* }\end{array}$ & $\begin{array}{c}\text { Nickel } \\
\text { in melt* }\end{array}$ \\
\hline 30 & 0.56 & 0.51 \\
50 & 0.92 & 2.92 \\
70 & 1.34 & 4.13 \\
\hline
\end{tabular}

* According to atomic absorption spectroscopy data.
Halide complexes of the $\mathrm{NiCl}_{4}^{2-}$ type can form in the nickel electrode regions that are subjected to intense corrosion and related to oxide film defects or structural imperfections in the nickel electrode.

However, XRD analysis of the nickel electrode surface after the end of experiments only revealed nickel oxide on part of the nickel electrode surface (Fig. 3), although the concentration of chloride ions and nickel ions in frozen samples of the molten salt increases with the chlorine content in the atmosphere (Table 4).

During anodic polarization, the rate of nickel ion transfer through the oxide increases and the metal oxidation rate increases due to an increase in the nickel vacancy migration. Moreover, the lithiation rate decreases, which increases the nickel oxidation rate. Lithium nickelate should form immediately after the formation of a dense oxide film. However, this process is strongly retarded at the initial stages, since the nickel vacancy concentration in the oxide layer is very low and a nickel chloride layer then hampers this process. The lithium concentration in the oxide begins to increase after the formation of an oxide layer, when the diffusion losses in the oxide and the salt phase are the same. The thickness of the layer of a stoichiometric composition should decrease continuously in time. The oxidation process accelerates by $3-5$ times. The total limiting current increases with temperature and the diffusion current of oxidation reduction decreases slightly. This behavior can be related to the fact that 
the transfer through the solid phase increases with temperature much stronger than the diffusion of oxygen in the melt.

Thus, the process kinetics for small polarization depends substantially on the ratio of the partial gas pressures. The current increases continuously with the potential, and the three-phase boundary is not involved in current generation.

\section{CONCLUSIONS}

(1) The substitution of chlorine for part of the gas atmosphere leads to an increase in the corrosion rate and the anodic dissolution of a nickel electrode.

(2) The corrosion process is localized and increases with the temperature and the polarization.

(3) The forming nickel oxide is structured on a nanoscale, which is revealed after the removal of a salt passivation layer upon washing.

\section{REFERENCES}

1. T. I. Manukhina, V. I. Sannikov, and O. P. Penyagina, Interaction of Metals and Alloys with Molten Alkali Metal Carbonates (UrO RAN, Yekaterinburg, 1999).

2. N. V. Korovin, General Chemistry (Vysshya Shkola, Moscow, 2002).

3. P. Antolini, "Behaviour of $\mathrm{Ni}, \mathrm{NiO}$ and $\mathrm{LiNiO}$ in molten alkali carbonates," J. Materials Science, No. 35, 1501-1505 (2000).

4. P. Tomczyk, J. Wyrwa, and M. Mosialek, "Electrochemical behaviour of $\mathrm{LiNiO}$ in molten carbonate eutectic," J. Electroanalytical Chemistry, No. 463, 7886 (1999).

5. S. Scaccia, "Investigation on $\mathrm{NiO}$ solubility in binary and ternary molten alkali metal carbonates containing additives,” J. Molecular Liquids, No. 116, 67-71 (2005).

6. K. Yamada and I. Uchida, "Solubility of in-situ oxidized $\mathrm{NiO}$ in $(62+38) \mathrm{mol} \%(\mathrm{Li}+\mathrm{K}) \mathrm{CO}_{3}$ melt under pressurized conditions," J. Electroanalytical Chemistry, No. 385, 57-61 (1995).

7. H. Ogura, Y. Ito, K. Murata, and T. Shirogami, "Dissolution of cathode nickel in molten carbonates in-situ measurement of dissolved $\mathrm{Ni}^{2+}$ concentration by means of anodic stripping method," Denki Kagaku 55 (5), 392397 (1987).

8. P. Tomczyk and M. Mosialek, "Electrochemistry of $\mathrm{Ni}$ oxidation in molten $\mathrm{Li}_{2} \mathrm{CO}_{3}+\mathrm{Na}_{2} \mathrm{CO}_{3}$," J. Electroanalytical Chemistry, No. 463, 72-77 (1999).

9. C. Belhomm, J. Devynek, and M. Cassir, "New insight in the cyclic voltammetric behavior of nickel in molten $\mathrm{Li}_{2} \mathrm{CO}_{3}-\mathrm{Na}_{2} \mathrm{CO}_{3}$ at $650^{\circ} \mathrm{C}, ” \quad J$. Electroanalytical Chemistry, No. 545, 7-17 (2003).

10. "Alkali insertion within $\mathrm{NiO} / \mathrm{Ni}$ electrode in contact with molten $\mathrm{Li}_{2} \mathrm{CO}_{3}-\mathrm{K}_{2} \mathrm{CO}_{3}$ and $\mathrm{Li}_{2} \mathrm{CO}_{3}-\mathrm{Na}_{2} \mathrm{CO}_{3}-$ $\mathrm{K}_{2} \mathrm{CO}_{3}$ at $650^{\circ} \mathrm{C}$," J. Power Sources, No. 63, 27-32 (1996).

11. S. I. Malevannyi and N. N. Batalov, "Oxidation of nickel in a eutectic carbonate mixture as a function of temperature and gas medium," in Proceedings of the 4th International Conference on Fundamental Problems of Electrochemical Power Engineering, Saratov (Izd. Saratov Univ., Saratov, 1999), p. 268.

12. A. B. Dubovtsev, "Process occurring at a nickel oxide anode during the electrolysis of a $\mathrm{CaCl}_{2}-\mathrm{CaO}$ melt," Extended Abstract of Cand. Sci. (Chem.) Dissertation, IVTE UrO RAN, Sverdlovsk, 1993.

13. A. N. Elshin, "Electrochemical behavior of the cathodes of high-temperature chemical current sources based on transition metal chlorides," Extended Abstract of Cand. Sci. (Chem.) Dissertation, IVTE UrO RAN, Sverdlovsk, 1990.

Translated by K. Shakhlevich 